\title{
The association of women's birth size with risk of molecular breast cancer subtypes: a cohort study
}

\author{
Marie S. Sandvei ${ }^{1,2}$, Signe Opdahl ${ }^{1}$, Marit Valla ${ }^{3,4}$, Pagona Lagiou ${ }^{5,6}$, Ellen Veronika Vesterfjell ${ }^{4}$, Tor Vikan Rise ${ }^{3,4}$, \\ Tina Syvertsen Overrein ${ }^{4}$, Anette H. Skjervold ${ }^{3}$, Monica J. Engstrøm ${ }^{3,7}$, Anna M. Bofin ${ }^{3}$ and Lars J. Vatten ${ }^{*}$
}

\begin{abstract}
Background: Because birth size appears to be positively associated with breast cancer risk, we have studied whether this risk may differ according to molecular breast cancer subtypes.

Methods: A cohort of 22,931 women born 1920-1966 were followed up for breast cancer occurrence from 1961 to 2012, and 870 were diagnosed during follow-up. Archival diagnostic material from 537 patients was available to determine molecular breast cancer subtype, specified as Luminal A, Luminal B (human epidermal growth factor receptor 2 (HER2)-), Luminal B (HER2+), HER2 type, and Triple negative (TN) breast cancer. Information on the women's birth weight, birth length and head circumference at birth was used to estimate hazard ratios (HR) with 95\% confidence intervals (Cl) for each molecular subtype, applying Cox regression, and stratified by maternal height.

Results: Birth length (per $2 \mathrm{~cm}$ increments) was positively associated with Luminal $A(H R=1.2,95 \% \mathrm{Cl}, 1.0-1.3)$, Luminal B (HER2+) (HR=1.3, 95\% Cl, 1.0-1.7), and TN breast cancer ( $H R=1.4,95 \% \mathrm{Cl}, 1.0-1.9)$. No clear association was found for birth weight and head circumference. The positive associations of birth length were restricted to women whose mothers were relatively tall (above population median).

Conclusion: We found a positive association of birth length with risk of Luminal A, Luminal B (HER2+) and TN breast cancer that appears to be restricted to women whose mothers were relatively tall. This may support the hypothesis that breast cancer risk is influenced by determinants of longitudinal growth and that this finding deserves further scrutiny.
\end{abstract}

Keywords: Breast cancer, Molecular subtypes, Epidemiology, Risk factors, Birth size, Birth length, Birth weight

\section{Background}

It has been demonstrated that breast cancer can be classified into different molecular subtypes using gene expression analysis [1]. However, molecular subtyping can also be achieved using surrogate markers for gene

\footnotetext{
* Correspondence: lars.vatten@ntnu.no

${ }^{1}$ Faculty of Medicine and Health Sciences, Department of Public Health and Nursing, Norwegian University of Science and Technology, Post box 8905, N-7491 Trondheim, Norway

Full list of author information is available at the end of the article
}

expression analysis [2-4]. Thus, using immumohistochemistry for detection of protein expression and in situ hybridisation for assessment of gene copy number, tumours can be classified into different subtypes. The differences between subtypes underline the heterogeneous nature of breast cancer, including different pathogeneses [5] and clinical course [1, 2].

Therefore, it is plausible that underlying risk factors may also differ between subtypes [6-9], indicating a need for subtype specific revision of breast cancer

(c) The Author(s). 2021 Open Access This article is licensed under a Creative Commons Attribution 4.0 International License, which permits use, sharing, adaptation, distribution and reproduction in any medium or format, as long as you give appropriate credit to the original author(s) and the source, provide a link to the Creative Commons licence, and indicate if changes were made. The images or other third party material in this article are included in the article's Creative Commons licence, unless indicated otherwise in a credit line to the material. If material is not included in the article's Creative Commons licence and your intended use is not permitted by statutory regulation or exceeds the permitted use, you will need to obtain permission directly from the copyright holder. To view a copy of this licence, visit http://creativecommons.org/licenses/by/4.0/. The Creative Commons Public Domain Dedication waiver (http://creativecommons.org/publicdomain/zero/1.0/) applies to the data made available in this article, unless otherwise stated in a credit line to the data. 
epidemiology, including possible consequences for prevention strategies. Recent results suggest that the reduced risk associated with early age at first birth, high parity and overweight before menopause, may also vary according to subtype [6-9],

Until recently, factors associated with birth size, i.e. birth weight, birth length and head circumference, have not been comprehensively studied in relation to risk of molecular subtypes of breast cancer. However, the association of birth size has been assessed in relation to hormone receptor status of the tumours; thus, there is some evidence for a positive association of birth weight with risk for ER positive breast cancer, but not for ER negative tumours [10].

The hypothesis that breast cancer may originate in utero is based on the fact that the mammary gland, which is not fully developed at birth, is exposed to high levels of intrauterine mammotropic hormones [11, 12]. This may increase the mammary gland-specific stem cell pool and eventually, the likelihood for cancer initiation later in life [13]. This hypothesis is supported by different lines of research [14-20] that combined may suggest a coherent sequence of plausible events. Thus, cord blood hormones could partly determine the size of the mammary stem cell pool and simultaneously influence fetal growth. Therefore, birth size may be positively associated with breast cancer risk later in life [17].

In this follow-up study, we used perinatal data from a cohort of Norwegian women born at one particular hospital between 1920 and 1966. During follow-up from 1961 to 2012, we studied women who were diagnosed with breast cancer at St. Olavs Hospital in Trondheim, Norway, and used surrogate markers applied to tissue microarrays of archival tumour tissue to determine the following molecular subtypes: Luminal A, Luminal B (HER2-), Luminal B (HER2+), and the non-luminal subtypes, the HER2 type and TN breast cancer. Our aim was to assess whether indicators of birth size are differentially associated with the risk for luminal and nonluminal subtypes.

\section{Methods}

A unique ID number was assigned to all Norwegian residents who were alive in 1960, and is assigned to all new residents from 1961 onwards. Each resident's record is continuously updated on vital status and residential and childbearing history through the National Registry. By combining the mother's name and the daughter's unique 11-digit number, we could identify women who were born at St. Olavs hospital, Trondheim University Hospital, between 1920 and 1966. After excluding 524 twins, 111 triplets, 32 women with missing information on plurality, and 12 women whose identity could not be determined with certainty, 22,931 women born between
1920 and 1966 were eligible for breast cancer follow-up until the end of 2012.

The reporting of cancer to the Cancer Registry of Norway is mandatory, and breast cancer is registered according to the international classification of diseases (ICD-7, code 170). For women born before 1941, breast cancer follow-up started on January 1st, 1961, and for women born after 1940, follow-up started at their 20th birthday. Follow-up ended when a cancer (at any site) was diagnosed, at emigration or at death (from any cause), or on December 31st, 2012, whichever occurred first. During follow-up, a total of 870 women were diagnosed with incident breast cancer. Among them, 598 were diagnosed at St Olav's Hospital; archival diagnostic tissue was available for all these 598 patients, and molecular subtyping proved to be successful for 537 of these cases.

From the birth record of each of the 22,931 women, we extracted information on birth weight $(\mathrm{g})$, birth length $(\mathrm{cm})$, head circumference $(\mathrm{cm})$, gestational age (in weeks or months), and birth order. We also extracted maternal information, including maternal age at childbearing, height, marital status, and socioeconomic status (occupation). (Baseline characteristics of the cohort members according to birth size are shown in Table 1).

From the National Registry, we collected information on childbearing history in adulthood for cohort members who were born in 1930 or later, and who were still residents in Trondheim. Thus, information on age at first birth and parity, both of which are associated with breast cancer risk, were included as co-variables for a subset $(78 \%)$ of the population.

\section{Molecular subtypes of breast cancer using archived diagnostic tissue}

Prior to molecular subtyping, each case was reexamined by two independent pathologists and classified into histological type and grade according to current guidelines. Sections from representative paraffin tumour blocks were stained with hematoxylinerythrosine-saffron (HES), and classified into histopathologic type and grade. Tumour size was correlated to information in the pathology report. Tissue microarrays (TMA) were constructed as previously described and referenced in detail by Engstrøm et al. (4) and Valla et al. (3).

Briefly, immuno-staining was performed for ER, PR, HER2, the proliferation marker Ki67, and Basal markers and EGFR. Negative controls were included in all staining runs. ER and PR were positive when $\geq 1 \%$ of tumor nuclei showed positive staining and Ki67 was counted in 500 tumor cells (hotspots), and considered high when $\geq 15 \%$ of nuclei were positive, both irrespective of staining intensity. Membranous staining for HER2 was scored 
Table 1 Baseline characteristics of cohort members, follow-up of 22,931 women

\begin{tabular}{|c|c|}
\hline & Number (\%) \\
\hline Mother's age at birth, mean (SD) & $28.0(6.1)$ \\
\hline \multicolumn{2}{|l|}{ Birth weight, g } \\
\hline Mean (SD) & $3446(508)$ \\
\hline$<3000 \mathrm{~g}$ & $3684(16.1)$ \\
\hline $3000-3499 \mathrm{~g}$ & $8657(37.8)$ \\
\hline $3500-3999 \mathrm{~g}$ & $7672(33.5)$ \\
\hline$\geq 4000 \mathrm{~g}$ & $2912(12.7)$ \\
\hline Missing & $6(0.03)$ \\
\hline \multicolumn{2}{|l|}{ Birth length, $\mathrm{cm}$} \\
\hline Mean (SD) & $50.5(2.1)$ \\
\hline$<49$ & $3190(13.9)$ \\
\hline 49 & 3055 (13.3) \\
\hline 50 & $5298(23.1)$ \\
\hline 51 & $4317(18.8)$ \\
\hline$\geq 52$ & 7066 (30.8) \\
\hline Missing & $5(0.02)$ \\
\hline \multicolumn{2}{|l|}{ Head circumference, cm } \\
\hline Mean (SD) & $34.8(1.5)$ \\
\hline$<34$ & $3849(16.8)$ \\
\hline 34 & $5397(23.5)$ \\
\hline 35 & $6408(27.9)$ \\
\hline 36 & $4642(20.2)$ \\
\hline$\geq 37$ & $2549(11.1)$ \\
\hline Missing & $86(0.4)$ \\
\hline Total & $22,931(100)$ \\
\hline
\end{tabular}

from 0 to +3 , and HER2 amplification was defined as a gene to chromosome ratio $\geq 2$.

For CK5 and EGFR, a staining index was calculated by multiplying the proportion of positive staining cells [1 $(<10 \%) ; 2(10-50 \%) ; 3$ (>50\%)] by staining pattern/intensity. Staining intensity for CK5 was defined as 0 (no staining); 1 (weak); 2 (moderate), and 3 (strong). For EGFR, membranous staining was 0 (no staining); 1 (faint, incomplete staining); 2 (moderate intensity, circumferential staining); 3 (strong intensity, circumferential staining), according to Dako PharmDX Kit guidelines. A staining index of $0-1$ was classified as negative, and 2-9 as positive.

Breast cancers were then reclassified into molecular subtypes by immunohistochemistry and fluorescence in situ hybridization, using the surrogate markers for oestrogen receptor (ER), progesterone receptor (PR), and the proliferation markers Ki67 and HER2. In addition, Cytokeratin 5 and Epidermal growth factor receptor 1 were used to differentiate between the Basal phenotype and the Five negative phenotype, however, we combined these subtypes into one, notified as TN.

ER was positive when $\geq 1 \%$ of tumour cells showed positive nuclear staining, and $\geq 10 \%$ for PR to be positive [21]. The molecular subtypes were defined as follows: Luminal A as (ER and/or PR+, HER2-, Ki67 <15\%); Luminal B (HER2-) as (ER and/or PR+, HER2-, Ki67 $\geq$ 15\%); Luminal B (HER2+) as (ER and/or PR+, HER2+); HER2 type as (ER and PR-, HER2+); and TN as (ER, PR and HER2-).

\section{Statistical methods}

We categorized the continuous or discrete birth size variables (birth weight, birth length, head circumference at birth) into approximately equally sized categories. We also examined the measures as quantitative increments of approximately one standard deviation (SD), i.e., $0.5 \mathrm{~kg}$ for birth weight, $2 \mathrm{~cm}$ for birth length, and $1.5 \mathrm{~cm}$ for head circumference.

We used Cox proportional hazards regression to study the association of the birth size indicators with risk of breast cancer subtypes, and precision of hazard ratios was estimated using 95\% confidence intervals (CI). Breast cancer cases that could not be subtyped were censored at the date of diagnosis. To examine if the associations between birth size and breast cancer risk differed by breast cancer subtype, we used the data augmentation method described by Lunn and McNeil [22]. A small $p$ value for heterogeneity from this test would indicate that the associations of birth size with breast cancer risk differs between tumour subtypes. Departure from the proportional hazards assumption was evaluated by Schönfelds residuals and by inspection of the log-log plots, and there were no clear violations to the assumption of proportionality. Attained age was used as the time scale in all analyses. In the multivariable analysis, we adjusted for gestational age, birth year in 5-year categories, and maternal birth order, age at birth, and socioeconomic status. In a subset of women (73\%), we considered whether adjustment for maternal height and the adult risk factors age at first birth and parity influenced the findings.

In a separate analysis, we assessed whether the association of birth size with risk of luminal and non-luminal subtypes differed by maternal height. In that analysis, maternal height was dichotomized at the population median $(163 \mathrm{~cm})$. We used the likelihood-ratio (LR) test to assess this possible effect modification.

The statistical analyses were conducted using STATA version 13.1 (StataCorp).

\section{Results}

Baseline characteristics of the cohort members according to birth size can be viewed in Table 1, and the 
distribution of breast cancer cases according to molecular subtype is shown in Table 2.

Table 3 shows the results for birth weight, birth length, and head circumference related to the risk for each molecular subtype. Birth length (per $2 \mathrm{~cm}$ increment) was positively associated with risk of Luminal A breast cancer $(\mathrm{HR}=1.2,95 \% \mathrm{CI}, 1.0-1.3)$, Luminal B (HER2+) breast cancer (HR $=1.3,95 \% \mathrm{CI}, 1.0-1.7)$, and $\mathrm{TN}$ breast cancer $(\mathrm{HR}=1.4,95 \% \mathrm{CI}, 1.0-1.9)$, but there were no clear associations with Luminal B (HER2-) and HER2 type ( $\mathrm{p}$ for heterogeneity 0.8 ). For birth weight and head circumference, there were no clear associations with risk for any of the molecular subtypes.

The multivariable results did not substantially differ from those only adjusting for attained age. The results restricted to the subset of women with information on maternal height and the adult risk factors age at first birth and parity (results not tabulated) were similar to the main results, however, for some categories, the number of participants was low in the subset analysis.

In a separate analysis (Table 4), we assessed whether associations of birth length (per $2 \mathrm{~cm}$ increment) and molecular breast cancer subtypes, indicated as luminal or non-luminal breast cancer, differed by maternal height (dichotomized at the median, $163 \mathrm{~cm}$ ). For nonluminal subtypes (HER2+ and TN), there was a positive association if mothers were $163 \mathrm{~cm}$ or taller $(\mathrm{HR}=1.5$, 95\% CI, $1.0-2.2$ per $2 \mathrm{~cm}$ ), and no association if mothers were shorter than $163 \mathrm{~cm}(\mathrm{HR}=1.0,95 \% \mathrm{CI}, 0.7-1.6$, per $2 \mathrm{~cm}$, LR-test $p=0.4)$. For luminal breast cancer (Luminal A and Luminal B (HER2-)), there was a similar, but weaker pattern: thus, there was a weak positive association if mothers were $163 \mathrm{~cm}$ or taller $(\mathrm{HR}=1.3,95 \%$ $\mathrm{CI}, 1.1-1.5$ per $2 \mathrm{~cm})$ and no clear association $(\mathrm{HR}=1.0$, 95\% CI, $0.9-1.2$ per $2 \mathrm{~cm}$ ) if maternal height was less than $163 \mathrm{~cm}$ (LR-test $p=0.7$ ).

Table 2 Descriptive statistics for the 537 breast cancer cases with molecular subtyping

\begin{tabular}{|c|c|c|c|c|c|c|}
\hline & Luminal $\mathrm{A}$ & Luminal B (HER-) & Luminal B (HER+) & HER 2 type & Triple negative & Total \\
\hline Number (\%) & $232(43.2)$ & $175(32.6)$ & $65(12.1)$ & $24(4.5)$ & $41(7.6)$ & $537(100)$ \\
\hline Mean age at diagnosis (SD) & $56.4(9.8)$ & $54.1(11.3)$ & $53.8(9.8)$ & $51.5(10.7)$ & $53.9(11.3)$ & $54.9(10.5)$ \\
\hline \multicolumn{7}{|l|}{ Tumour grade (\%) } \\
\hline 1 & $58(25.0)$ & $3(1.7)$ & $1(1.5)$ & $1(4.2)$ & 0 & $63(11.7)$ \\
\hline 2 & $155(66.8)$ & $93(53.1)$ & $19(29.2)$ & $3(12.5)$ & $6(14.6)$ & $276(51.4)$ \\
\hline 3 & $19(8.2)$ & $79(45.1)$ & $45(69.2)$ & $20(83.3)$ & $35(85.4)$ & $198(36.9)$ \\
\hline \multicolumn{7}{|l|}{ Histopathological type } \\
\hline Ductal & $198(85.3)$ & $155(88.6)$ & $60(92.3)$ & $18(75.0)$ & $31(75.6)$ & $462(86.0)$ \\
\hline Lobular & $24(10.3)$ & $8(4.6)$ & $2(3.1)$ & 0 & 0 & $34(6.3)$ \\
\hline Tubular & $2(0.9)$ & 0 & 0 & 0 & 0 & $2(0.4)$ \\
\hline Mucinous & $6(2.6)$ & $2(1.1)$ & 0 & 0 & 0 & $8(1.5)$ \\
\hline Medullary & 0 & $6(3.4)$ & $3(4.6)$ & $6(25.0)$ & $6(14.6)$ & $21(3.9)$ \\
\hline Papillary & 0 & $1(0.6)$ & 0 & 0 & 0 & $1(0.2)$ \\
\hline Metaplastic & 0 & 0 & 0 & 0 & $2(4.9)$ & $2(0.4)$ \\
\hline Other & $2(0.9)$ & $3(1.7)$ & 0 & 0 & $2(4.9)$ & $7(1.3)$ \\
\hline \multicolumn{7}{|l|}{ Tumour size, cm (\%) } \\
\hline$<2$ & $151(65.1)$ & $79(45.1)$ & $26(40.0)$ & $4(16.7)$ & $14(34.2)$ & $274(51.0)$ \\
\hline $2-5$ & $49(21.1)$ & $59(33.7)$ & $28(43.1)$ & $10(41.7)$ & $16(39.0)$ & $162(30.2)$ \\
\hline$>5$ & $5(2.2)$ & $7(4.0)$ & $1(1.5)$ & 0 & $2(4.9)$ & $15(2.8)$ \\
\hline Uncertain & 27 (11.6) & $30(17.1)$ & $10(15.4)$ & $10(41.7)$ & $9(22.0)$ & $86(16.0)$ \\
\hline \multicolumn{7}{|l|}{ Stage } \\
\hline 0 & 0 & 0 & 0 & $1(4.2)$ & 0 & $1(0.2)$ \\
\hline । & $105(45.3)$ & $57(32.6)$ & $14(21.5)$ & $8(33.3)$ & $17(41.5)$ & $201(37.4)$ \\
\hline$\|$ & $92(39.7)$ & $90(51.4)$ & $37(56.9)$ & $12(50.0)$ & $14(34.2)$ & $245(45.6)$ \\
\hline III & $10(4.3)$ & $8(4.6)$ & $3(4.6)$ & $1(4.2)$ & $3(7.3)$ & $25(4.7)$ \\
\hline IV & $4(1.7)$ & $4(2.3)$ & $4(6.2)$ & $1(4.2)$ & $1(2.4)$ & $12(2.6)$ \\
\hline Unknown & $21(9.1)$ & $16(9.1)$ & $7(10.8)$ & $1(4.2)$ & $6(14.6)$ & $51(9.5)$ \\
\hline
\end{tabular}


Table $\mathbf{3}$ Indicators of birth size associated with risk of molecular subtypes of breast cancer

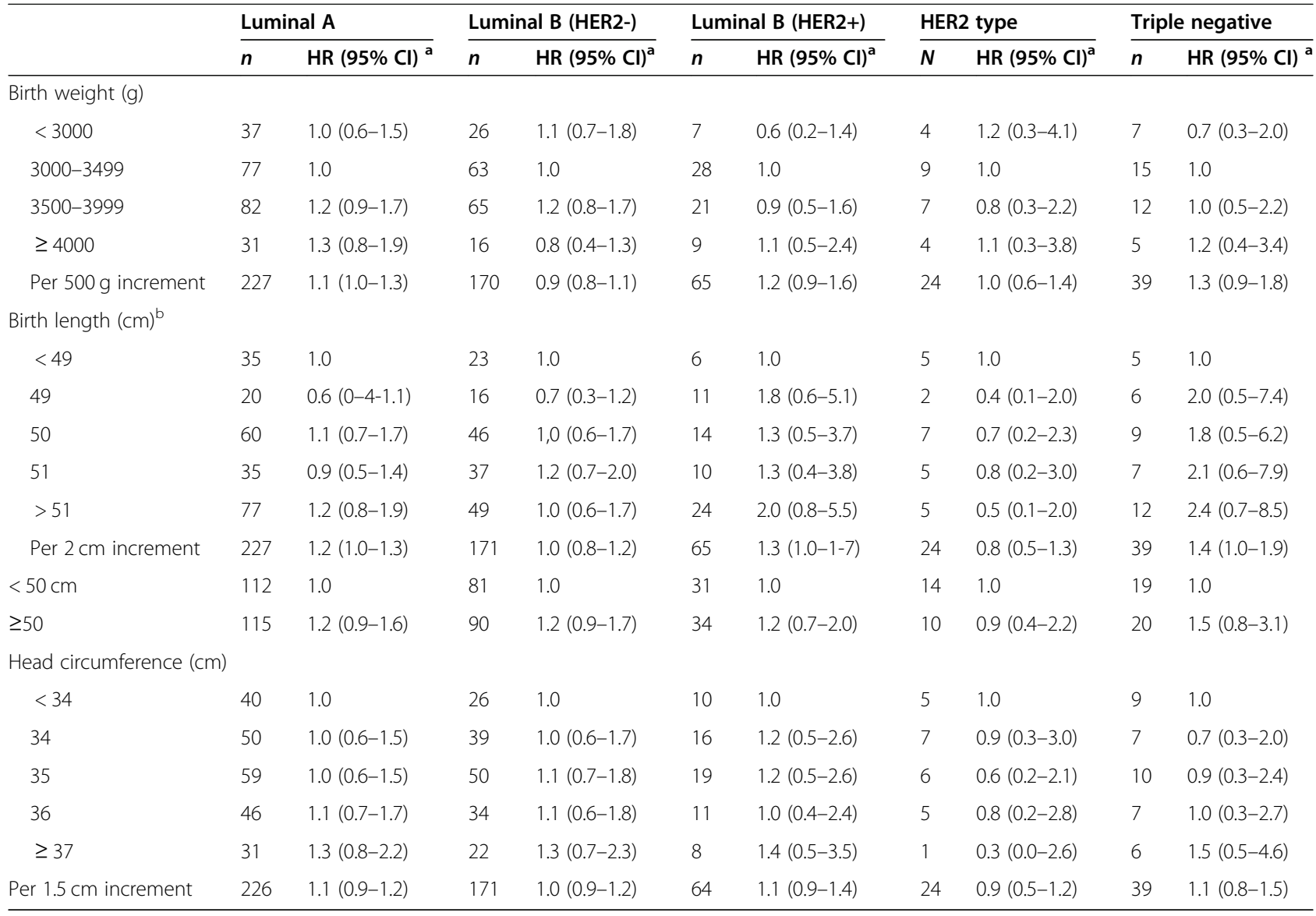

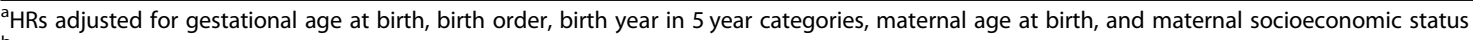

${ }^{\mathrm{b}}$ Lunn McNeil likelihood-ratio test, $p=0.7$

\section{Discussion}

In this long-term follow-up for breast cancer, we found that birth length was positively associated with risk both for Luminal A, Luminal B (HER2+), and TN breast cancer, and the results suggest that these associations displayed a homogeneous pattern, based on the test for heterogeneity. We also found evidence that the positive association of birth length was present in women whose mothers were relatively tall (at population median or taller).

To understand these findings, the literature does not provide any direct help, because risk of molecular breast cancer has not been previously studied in the context of birth size. However, one study has assessed birth weight with risk for breast cancer according to hormone receptor status.

[10], and found that a positive association with risk for ER positive, but not for ER negative breast cancer. Although that study used birth weight as indicator for birth size, and our results suggested a positive association limited to birth length, the luminal subtypes of breast cancer overlap to a substantial degree with ER positive tumours, and the results may therefore support each other.

However, the positive association that we found for birth length was also present for the HER+ subtype and for triple negative (TN) breast cancer. Moreover, the strength of the positive associations was rather similar for the different subtypes.

The major strength of the present study is the large cohort of women born between 1920 and 1966, and the long-term breast cancer follow-up provided by record linkage with the Cancer Registry of Norway. The notification of cancer to the Cancer Registry of Norway is mandatory and regulated by law, and the registration is virtually complete [23]. Baseline information on birth size was measured and stored in birth records that we have transcribed and computerized, and later combined with adult information about age at first birth and parity. We used archival diagnostic tumour tissue to determine the molecular subtype, using a predetermined subtyping algorithm [3, 4], and the same antibodies and cut-off levels for all cases. However, in the present study, we classified the Basal phenotype and the Five negative 


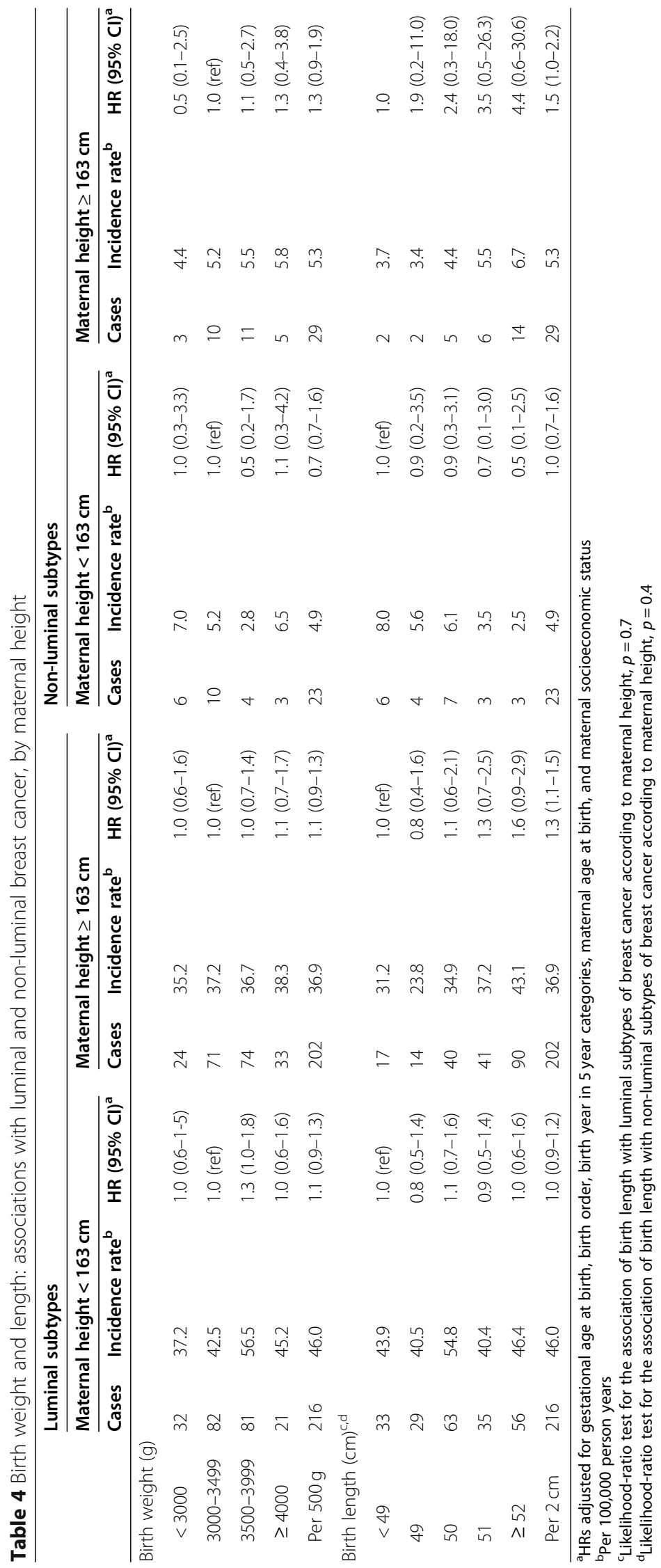


phenotype as TN in order to avoid subtypes with relatively few cases.

Limitations of the study include lack of longitudinal information on childhood and adolescent growth, including height and weight gain, which could be intermediate factors, and have been shown to be associated with breast cancer risk in previous studies [24, 25]. For ethical reasons, we were not allowed to contact cohort members who were still alive to update relevant information. Another limitation of our study is the lack of biological material from the time of birth. Possibly, measurements of cord blood hormones would be a useful approach to address the intrauterine roots of breast cancer more directly [26], but because participants were born between 1920 and 1966, biological material from their births could not be expected to be available. Nonetheless, measures of birth size (birth weight, birth length, head circumference) could be interpreted as proxy factors for intrauterine growth and hormonal exposures in utero [26, 27]. Lastly, there is always a concern linked to the representativeness of cases in a single observational study, and therefore, our results need verification in other studies.

The main finding of this study suggests that birth length is positively associated with risk of Luminal A and Luminal B (HER2+) breast cancer, both of which are ER positive tumours, and with TN breast cancer, which is ER negative. Interestingly, associations of birth length were not consistent across ER and HER2 status, as indicated by the lack of association for the HER2 type, which is ER negative, and the Luminal B (HER2-) type, which is ER positive. This suggests that the association of birth length with breast cancer risk is still unresolved and may involve other factors than ER and HER2. Despite the relatively large study cohort, the number of incident cases was still moderate, and the results of a larger study, or from other cohort studies, would most likely contribute with useful insights that would nuance our findings.

\section{Conclusions}

The fact that birth length was the only measure of birth size that was associated with any of the subtypes, may point to longitudinal growth as particularly important, regardless of ER status. It is also compelling that the positive association of birth length was present only among women whose mothers were relatively tall. This may further support the possibility that determinants of longitudinal growth may be at the core of the intrauterine roots of breast cancer $[11,28]$.

\section{Abbreviations}

Cl: Confidence interval; ER: Oestrogen receptor; HER2: Human epidermal growth factor receptor 2; HR: Hazard ratio; PR: Progesterone receptor

\section{Acknowledgements}

The authors want to thank senior biomedical engineer Borgny Ytterhus, Department of Clinical and Molecular Medicine, NTNU, for excellent laboratory work

\section{Authors' contributions}

MSS and SO performed the statistical analyses, interpreted the results and revised the manuscript for important intellectual content; $A M B$ designed the subtyping algorithm and selected biomarkers; MV, AHS, MJE and AMB carried out biomarker analysis and molecular subtyping; EW, TVR, TSO, MV and AMB typed and graded all cases; MV, AMB and PL interpreted the results and revised the manuscript for important intellectual content; LJV conceived and designed the study, handled funding and supervision, interpreted the results, and drafted the manuscript. All authors read and approved the final manuscript.

\section{Funding}

The original study cohort was established by financial support given by the National Cancer Institute (US) to Dimitrios Trichopoulos and Lars J. Vatten in 1998 (NIH grant RO1 78761). For the current study, MSS received a grant from the Norwegian Cancer Society. The other authors who participated in this study were financed through other means than the funding given to support this study. The funding bodies played no role in the design of the study and collection, analysis, and interpretation of data and in writing of the manuscript.

\section{Availability of data and materials}

The data sets generated and analysed during the current study are not publicly available due to privacy reasons, but anonymized data may be available from the corresponding author on reasonable request and after approval of the regional ethical committee.

\section{Declarations}

\section{Ethics approval and consent to participate}

The original raw birth size data of the participants were obtained by the corresponding author as part of a cohort study of birth size and breast cancer risk that was conducted and ethically approved in 1997. At the time, we obtained approval for the study, by applying to the Norwegian Data Inspectorate and the Norwegian Directorate of Health. In addition, the study was approved by the Regional Committee for Medical Research Ethics, administered by the Faculty of Medicine, the Norwegian University of Science and Technology in Trondheim, Norway. Legislation for conducting medical research was altered in Norway in 2008, and four regional ethics committees were given authority to approve such research. Thus, the relevant regional committee waivered the need to consent to participate in the follow-up of the current study (requiring linkage to the Norwegian Cancer Registry) and approved the re-analysis of archived diagnostic breast cancer material that enabled us to study molecular subtypes of breast cancer. Thus, the present study was approved by the Regional Committee for Medical and Health Research Ethics (REC Central /IRB: 836/2009), at the Norwegian University of Science and Technology, Trondheim, Norway.

\section{Consent for publication}

Not applicable.

\section{Competing interests}

The authors declare that they have no competing interests.

\section{Author details}

${ }^{1}$ Faculty of Medicine and Health Sciences, Department of Public Health and Nursing, Norwegian University of Science and Technology, Post box 8905, N-7491 Trondheim, Norway. ${ }^{2}$ The Cancer Clinic, St. Olavs Hospital, Trondheim University Hospital, Trondheim, Norway. ${ }^{3}$ NTNU, Faculty of Medicine and Health Sciences, Department of Clinical and Molecular Medicine, Faculty of Medicine and Health Sciences, Norwegian University of Science and Technology, Post box 8905, N-7491 Trondheim, Norway. ${ }^{4}$ Department of Pathology, St. Olavs Hospital HF, Trondheim University Hospital, Postboks 3250 Torgarden, 7006 Trondheim, Norway. ${ }^{5}$ Department of Hygiene, Epidemiology and Medical Statistics, School of Medicine, National and Kapodistrian University of Athens, 75 M. Asias Street, Goudi, GR-115 27 
Athens, Greece. ${ }^{6}$ Department of Epidemiology, Harvard School of Public Health, Boston, USA. 'Department of Breast and Endocrine Surgery, St. Olavs Hospital, Trondheim University Hospital, Trondheim, Norway.

Received: 25 August 2020 Accepted: 12 March 2021

Published online: 23 March 2021

\section{References}

1. Sorlie T, Perou CM, Tibshirani R, Aas T, Geisler S, Johnsen H, et al. Gene expression patterns of breast carcinomas distinguish tumor subclasses with clinical implications. Proc Natl Acad Sci U S A. 2001:98(19):10869-74.

2. Blows FM, Driver KE, Schmidt MK, Broeks A, van Leeuwen FE, Wesseling J, et al. Subtyping of breast cancer by immunohistochemistry to investigate a relationship between subtype and short and long term survival: a collaborative analysis of data for 10,159 cases from 12 studies. PLoS Med. 2010;7(5):e1000279.

3. Valla M, Vatten LJ, Engstrom MJ, Haugen OA, Akslen LA, Bjorngaard JH, et al Molecular Subtypes of Breast Cancer: Long-term Incidence Trends and Prognostic Differences. Cancer Epidemiol Biomark Prev. 2016;25(12):1625-34.

4. Engstrom MJ, Opdahl S, Hagen Al, Romundstad PR, Akslen LA, Haugen OA, et al. Molecular subtypes, histopathological grade and survival in a historic cohort of breast cancer patients. Breast Cancer Res Treat. 2013;140(3):46373.

5. Prat A, Perou CM. Mammary development meets cancer genomics. Nat Med. 2009;15(8):842-4

6. Yang XR, Chang-Claude J, Goode EL, Couch FJ, Nevanlinna H, Milne RL, et al. Associations of breast cancer risk factors with tumor subtypes: a pooled analysis from the Breast Cancer Association Consortium studies. J Natl Cancer Inst. 2011;103(3):250-63.

7. Tamimi RM, Colditz GA, Hazra A, Baer HJ, Hankinson SE, Rosner B, et al. Traditional breast cancer risk factors in relation to molecular subtypes of breast cancer. Breast Cancer Res Treat. 2012;131(1):159-67.

8. Sisti JS, Collins LC, Beck AH, Tamimi RM, Rosner BA, Eliassen AH. Reproductive risk factors in relation to molecular subtypes of breast cancer: Results from the nurses' health studies. Int J Cancer. 2016:138(10):2346-56.

9. Fortner RT, Sisti J, Chai B, Collins LC, Rosner B, Hankinson SE, et al. Parity, breastfeeding, and breast cancer risk by hormone receptor status and molecular phenotype: results from the Nurses' Health Studies. Breast Cancer Res. 2019;21(1):40

10. Hurley S, Goldberg D, Von Behren J, Quach T, Layefsky M, Reynolds P. Birth size and breast cancer risk among young California-born women. Cancer Causes Control. 2011;22(10):1461-70.

11. Trichopoulos D. Hypothesis: does breast cancer originate in utero? Lancet. 1990:335(8695):939-40.

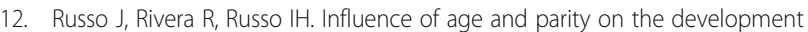
of the human breast. Breast Cancer Res Treat. 1992:23(3):211-8.

13. Trichopoulos D, Adami HO, Ekbom A, Hsieh CC, Lagiou P. Early life events and conditions and breast cancer risk: from epidemiology to etiology. Int $J$ Cancer. 2008;122(3):481-5.

14. Hoover RN, Hyer M, Pfeiffer RM, Adam E, Bond B, Cheville AL, et al. Adverse health outcomes in women exposed in utero to diethylstilbestrol. N Engl J Med. 2011:365(14):1304-14.

15. Adami HO, Lagiou P, Trichopoulos D. Breast cancer following diethylstilbestrol exposure in utero: insights from a tragedy. Eur J Epidemiol. 2012;27(1):1-3

16. Lagiou P, Samoli E, Okulicz W, Xu B, Lagiou A, Lipworth L, et al. Maternal and cord blood hormone levels in the United States and China and the intrauterine origin of breast cancer. Ann Oncol. 2011;22(5):1102-8.

17. Silva Idos S, De Stavola B, McCormack V. Birth size and breast cancer risk: reanalysis of individual participant data from 32 studies. PLoS Med. 2008;5(9): e193.

18. Park SK, Kang D, McGlynn KA, Garcia-Closas M, Kim Y, Yoo KY, et al. Intrauterine environments and breast cancer risk: meta-analysis and systematic review. Breast Cancer Res. 2008;10(1):R8

19. Savarese TM, Strohsnitter WC, Low HP, Liu Q, Baik I, Okulicz W, et al. Correlation of umbilical cord blood hormones and growth factors with stem cell potential: implications for the prenatal origin of breast cancer hypothesis. Breast Cancer Res. 2007;9(3):R29.

20. Strohsnitter WC, Savarese TM, Low HP, Chelmow DP, Lagiou P, Lambe M, et al. Correlation of umbilical cord blood haematopoietic stem and progenitor cell levels with birth weight: implications for a prenatal influence on cancer risk. Br J Cancer. 2008;98(3):660-3.

21. Hammond ME, Hayes DF, Dowsett M, Allred DC, Hagerty KL, Badve S, et al. American Society of Clinical Oncology/College of American Pathologists guideline recommendations for immunohistochemical testing of estrogen and progesterone receptors in breast cancer. Arch Pathol Lab Med. 2010; 134(6):907-22.

22. Lunn M, McNeil D. Applying Cox regression to competing risks. Biometrics. 1995:51(2):524-32.

23. Larsen IK, Smastuen M, Johannesen TB, Langmark F, Parkin DM, Bray F, et al. Data quality at the Cancer Registry of Norway: an overview of comparability, completeness, validity and timeliness. Eur J Cancer. 2009;45(7):1218-31.

24. Ahlgren M, Melbye M, Wohlfahrt J, Sorensen TI. Growth patterns and the risk of breast cancer in women. N Engl J Med. 2004;351(16):1619-26.

25. Baer HJ, Tworoger SS, Hankinson SE, Willett WC. Body fatness at young ages and risk of breast cancer throughout life. Am J Epidemiol. 2010;171(11): 1183-94.

26. Lagiou P, Hsieh CC, Lipworth L, Samoli E, Okulicz W, Troisi R, et al. Insulinlike growth factor levels in cord blood, birth weight and breast cancer risk. Br J Cancer. 2009:100(11):1794-8.

27. Lagiou P, Samoli E, Hsieh CC, Lagiou A, Xu B, Yu GP, et al. Maternal and cord blood hormones in relation to birth size. Eur J Epidemiol. 2014;29(5): 343-51

28. Lagiou P, Trichopoulos D. Hsieh CC. Is maternal height a risk factor for breast cancer? Eur J Cancer Prev. 2013;22(5):389-90.

\section{Publisher's Note}

Springer Nature remains neutral with regard to jurisdictional claims in published maps and institutional affiliations.

Ready to submit your research? Choose BMC and benefit from:

- fast, convenient online submission

- thorough peer review by experienced researchers in your field

- rapid publication on acceptance

- support for research data, including large and complex data types

- gold Open Access which fosters wider collaboration and increased citations

- maximum visibility for your research: over $100 \mathrm{M}$ website views per year

At BMC, research is always in progress.

Learn more biomedcentral.com/submissions 